\section{Final diagnosis}

Infantile cortical hyperostosis (Caffey's disease).
Keywords: peri-osteitis; infantile cortical hyperostosis; Caffey's disease
1 Caffey J, Silverman W. Infantile cortical hyperostosis. Preliminary report in a new syndrome. $A f R$ 1945;54:1.

2 Van Buskirk FW, Tampas JP, Peterson OS Jr. Infantile cortical hyperostosis. An enquiry into its familial aspects. $A \mathcal{F R}$ 1961;85:613.
3 Finsterbush A, Rang $M$. Infantile cortical hyperostosis. Followup of 29 cases. Acta Orthop Scand 1975;46:727.

4 Jackson DR, Lyne ED. Infantile cortical hyperostosis case report $\mathcal{F}$ Bone foint Surg 1979;61-A;770.

\title{
Aortic valve mass and sudden blindness
}

\author{
Shaul Atar, Lev Bloch, Tiberio Rosenfeld
}

A 63-year-old man presented with a sudden and painless loss of vision in his left eye. He had no history of heart disease or arrhythmias, diabetes mellitus, hyperlipidaemia, hypertension or smoking. On admission his blood pressure was $160 / 90 \mathrm{mmHg}$, and his physical examination was unremarkable. Electrocardiography demonstrated normal sinus rhythm, with no signs of ischaemia or left ventricular hypertrophy. Ophthalmologic examination revealed no light perception in his left eye, and a pale and oedematous retina. The findings suggested a high probability of an embolic central retinal artery occlusion. Therefore 1.5 million units of streptokinase were given, with only a slight improvement of his vision. A transthoracic echocardiography (TTE) and carotid ultrasound performed the next day were interpreted as normal. The patient was discharged on warfarin therapy. While at home, he continued to have episodes of lightheadedness, dizziness and visual hallucinations once or twice a week. Transoesophageal echocardiography (TEE) was performed a few weeks after discharge (figure).

\author{
Department of \\ Cardiology, Ha'emek \\ Medical Center, 18101 \\ Afula, Israel \\ S Atar \\ L Bloch \\ T Rosenfeld \\ Correspondence to Dr Shaul \\ Atar, Division of Cardiology, \\ Room \#5314, Cedars-Sinai \\ Medical Center, 8700 \\ Beverly Blvd, Los Angeles, \\ CA 90048, USA
}

Accepted 16 December 1997

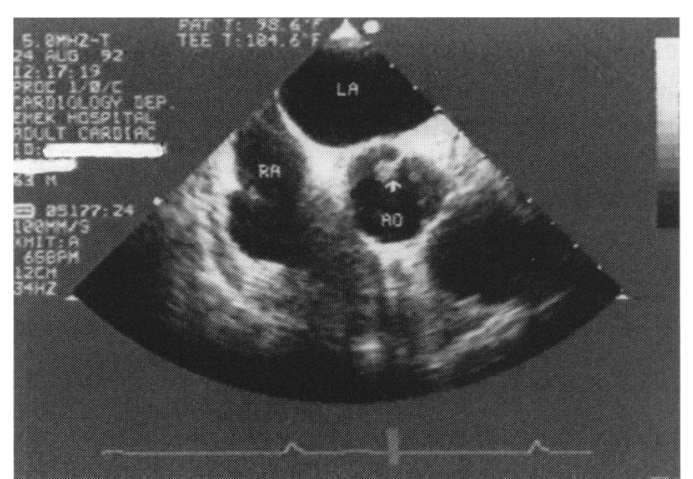

\section{Questions}

1 What abnormality is shown in the aorta on the echocardiogram?

2 What is the differential diagnosis?

3 What is the most probable diagnosis, considering the echocardiographic findings and the patient's history and physical findings ?

4 What is the treatment of choice? 
Answers

QUESTION 1

A $7 \times 7 \mathrm{~mm}$ papillary mass can be seen attached to the aortic face of the non-coronary aortic cusp.

\section{QUESTION 2}

The differential diagnosis is cardiac tumour, aortic valve vegetation, thrombus, or calcified atherosclerotic mass.

\section{QUESTION 3}

The most probable diagnosis is a papillary fibroelastoma.

\section{QUESTION 4}

The recommended treatment is immediate surgical excision of the mass.

\section{Discussion}

Papillary fibroelastomas are rare, benign and avascular cardiac tumours, derived from normal components of the endocardium. ${ }^{1}$ They were found to be the most common primary cardiac valve tumour in a literature review of 128 case reports. ${ }^{2}$ Most tumours are attached to either side of the cardiac valves, but may also be located on the surface of papillary muscles, chordae tendinae, ventricular septum and endocardium of all cardiac chambers. They are mostly identified on autopsy, but rarely during life. Most of the patients who were diagnosed by echocardiography, had prior symptoms stroke, myocardial infarction, or sudden death. $^{3}$

The possibility of a cardiac vegetation, a thrombus, or an atherosclerotic aortic calcified mass were considered unlikely in our patient, since these were not supported by the clinical and echocardiographic findings. TTE performed one day after his presentation was

1 Shub C, Tajik AJ, Seward JB, Edwards WD, Pruitt RD, Orszulak TA, Pluth JR. Cardiac papillary fibroelastomas. Twodimensional echocardiographic recognition. Mayo Clin Proc 1981;56:629-33.

2 Ryan PE, Obeid AL, Parker EB Jr. Primary cardiac valve tumors. f Heart Valve Dis 1995;4:222-6.

3 Israel DH, Sherman W, Ambrose JA, Sharma S, Harpaz N, Robbins M. Dynamic coronary ostial obstruction due to

\section{Learning points}

- papillary fibroelastomas are rare, but are the most prevalent primary cardiac valve tumours

- sudden unilateral blindness may be of an embolic source

- TEE should be performed whenever systemic embolisation is suspected and other non-invasive tests are unrevealing

- most papillary fibroelastomas are asymptomatic, but once diagnosed they should be excised immediately

interpreted as normal, and the tumour was only discovered a few weeks later on TEE. The patient was sent for immediate surgery and the tumour was excised successfully. Histological examination confirmed the diagnosis of papillary fibroelastoma. He has had no further embolic events in 5 years of follow-up.

It has been suggested that TEE should be performed in every patient with signs and symptoms of systemic embolisation and a normal cardiac history, physical findings, and normal non-invasive studies or TTE. ${ }^{4}$ We suggest that cardiac valve tumours, mainly papillary fibroelastoma, should be included in the differential diagnosis of ocular or systemic embolic events. Once diagnosed, even in an asymptomatic patient, they should be excised immediately.

\section{Final diagnosis}

Papillary fibroelastoma of the aortic valve, causing an embolic central retinal artery occlusion.

Keywords: papillary fibroelastoma; blindness; transoesophageal echocardiography

papillary fibroelastoma leading to myocardial ischemia and infarction. Am 7 Cardiol 1991;67:104-5.

4 Brown RD Jr, Khanderia BK, Edwards WD. Cardiac papillary fibroelastoma: a treatable cause of transient ischemic attack and ischemic stroke detected by transesophagea echocardiography. Mayo Clin Proc 1995;70:863-8. 